DIW BERLIN

Discussion Papers
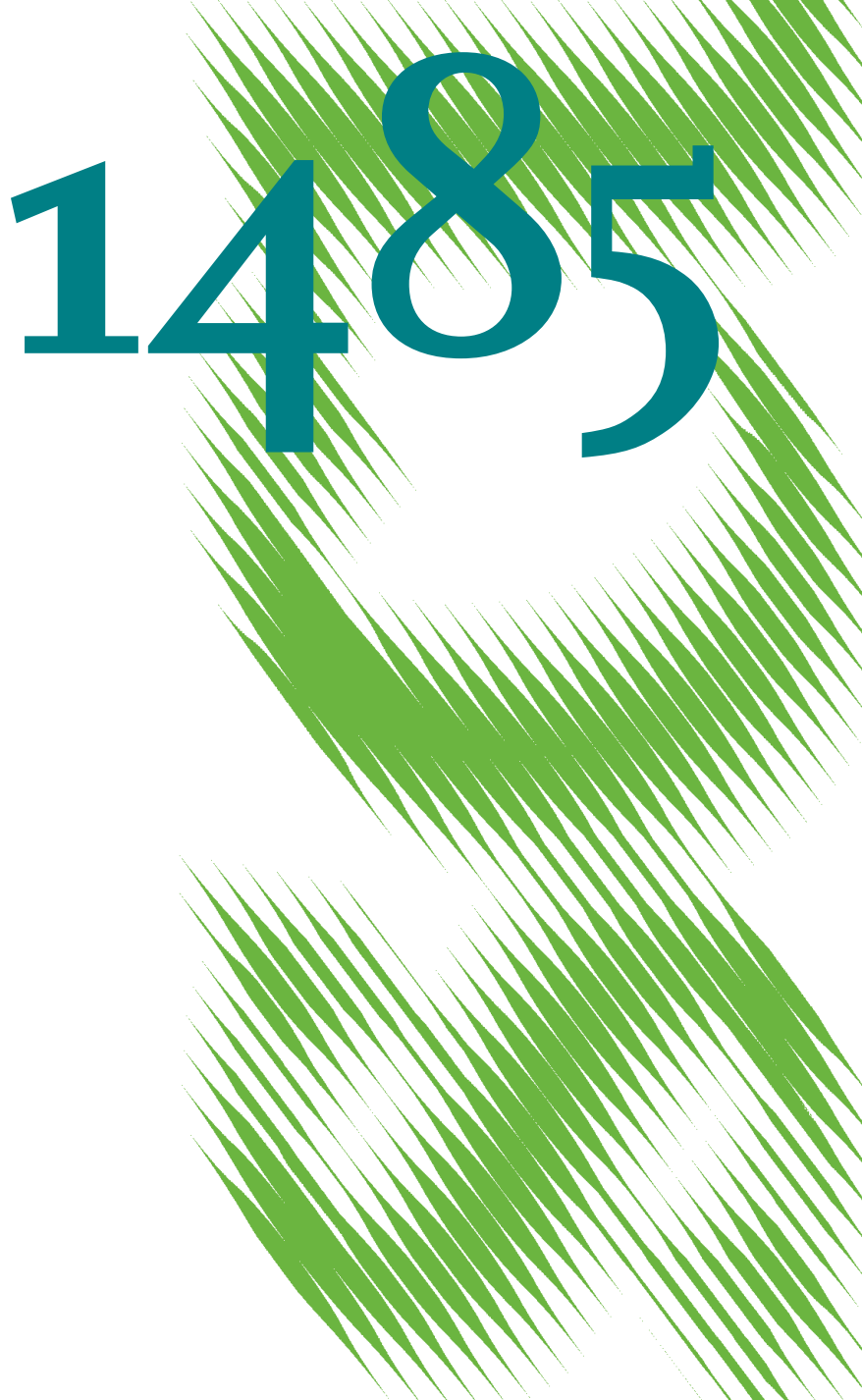

MMMMMMMMMM

The Impact of Wind Power Support Schemes on Technology Choices 
Opinions expressed in this paper are those of the author(s) and do not necessarily reflect views of the institute.

IMPRESSUM

(C) DIW Berlin, 2015

DIW Berlin

German Institute for Economic Research

Mohrenstr. 58

10117 Berlin

Tel. +49 (30) $89789-0$

Fax +49 (30) $89789-200$

http://www.diw.de

ISSN electronic edition 1619-4535

Papers can be downloaded free of charge from the DIW Berlin website:

http://www.diw.de/discussionpapers

Discussion Papers of DIW Berlin are indexed in RePEc and SSRN:

http://ideas.repec.org/s/diw/diwwpp.html

http://www.ssrn.com/link/DIW-Berlin-German-Inst-Econ-Res.html 


\title{
The Impact of Wind Power Support Schemes on Technology Choices
}

\author{
Nils May*
}

June 10, 2015

\begin{abstract}
Germany changed renewable remuneration for wind power from a fixed Feed-In Tariff (FIT) to a floating Market Premium Scheme (MPS) in 2012. One aim of this adjustment was to better align the supply of generated wind electricity with the demand for it, e.g. through more system-friendly wind turbine technology choices. In energy systems with a high share of variable renewable energies, such turbines produce a higher share of their production at lower wind speeds and thus can reduce the need for alternative flexibility options like back-up capacity, storage, grid extensions and demand side measures. However, based on a wind power investment model, I show that the MPS fails to convey strong enough incentives to project developers to significantly alter their investment decisions as long as these base their investments on current electricity market price profiles and are limited by their access to risk-averse project finance.

One reform proposal to support the installation of system-friendly turbines is a change in the production volume-based benchmark approach which plays an integral part in both the fixed FIT and the MPS. The investment model indicates that such a revised policy can incentivize the deployment of moderately more system-friendly wind power technologies at some locations. An alternative option is to shift to a production value-based benchmark approach. It directly reflects the future additional market value of system-friendly turbines in today's remuneration structure. Thus, this approach sets incentives also for investors without perfect foresight - or with financing constraints - to deploy more systemfriendly turbines that meet the requirements of power systems with increasing shares of wind power.
\end{abstract}

Key words: Renewable Energies; Wind Power Technology; Feed-in Tariff; Project Finance; Market Premium.

JEL classification: Q42, Q55, O38

${ }^{*}$ Climate Policy Department, German Institute for Economic Research Berlin (DIW Berlin), Mohrenstrasse 58, 10117 Berlin, Germany. Email: nmay@diw.de 


\section{Introduction}

Over the last decade, global deployment of renewable energies like wind and solar has grown tremendously. Germany has been at the forefront of this development and has passed the Energiewende towards renewable energies. Those represented about 28 percent of gross electricity consumption in 2014 (Bundesministerium für Wirtschaft und Energie, 2015). The official national goal is a renewable share of at least 80 percent by 2050. To achieve this, the German government has specified a capacity target of $2.5 \mathrm{GW}$ of newly installed onshore wind capacity annually over the next years (Bundestag, 2014). If this range is not met, the support scheme's payments are decreased/increased as to steer installations into the desired range.

However, the volatile power generation of solar and wind power poses new challenges and costs to an energy system built for thermal power plants. In times of little sunshine and generally low wind speeds, back-up capacity, storage and demand side response measures can be required in order to meet the rather inelastic- demand for electricity. Those remedies come at costs. They are encouraged through significant price spreads, supporting policy frameworks and resulting business models.

Another potential option to better align the generation of fluctuating energy sources and the demand for it is through the policies concerning renewable energy deployment. So far, fixed Feed-In-Tariffs (FIT) have prevailed in fostering the growth of both solar and wind power. Through the Renewable Energy Sources Act, such a FIT was introduced in Germany in 2000. Under the FIT, investors received a specific remuneration per produced $\mathrm{kWh}$. This remuneration proportionally increases with the amount of electricity they generate ${ }^{1}$. Investors are indifferent to the actual electricity wholesale prices. Yet, the wholesale price reflects to a certain degree if supply is low and demand is high (ceteris paribus higher prices), and vice versa. Summarized, fixed FITs provide investors with a lot of certainty, but no incentive to select system-friendly wind turbines.

The floating Market Premium Scheme (MPS) aims to accomplish such an alignment for wind power generation. Germany first introduced the floating MPS on a voluntary basis in 2012, and rendered it obligatory in August 2014, thus abolishing the fixed FIT except for very small installations. Wind power operators are to sell their electricity themselves or hire a direct-marketing service provider for this purpose. Thus, they have stronger incentives to forecast their production correctly (Tisdale et al., 2014). The floating MPS exposes operators to the wholesale electricity market price, and pays them a floating premium on top of it. The overall payment is based on how strongly a turbine's generation correlates with overall wind power production, and whether deviations from it occur in hours of lower or higher electricity prices. Ceteris paribus, a lower supply of wind power means a lower supply of electricity, so that the pricesetting power plant has a higher marginal cost. This yields higher electricity prices. Therefore, the covariance between a turbine's electricity generation with the overall German wind feed-in plays an important role in determining an investor's revenues.

Potentially, this covariance can be influenced by two factors: Firstly, the

\footnotetext{
${ }^{1}$ Due to the adjustments of the production volume-based benchmark approach, this does not exactly hold true in Germany. A higher generation can lead to a shorter extension of the higher FIT, and thus can also partially lower remuneration, cp. section 2.3.
} 
location of the turbine. The majority of turbines in Germany are located in the north/north-east of the country (Deutsche WindGuard, 2015). This implies that turbines in southern Germany could possibly deviate from the overall production, as it is dominated by northern German wind turbines. Grothe and Müsgens (2013) find that under the MPS, locations in Germany gain or lose to different degrees, depending on their correlation with the overall German feedin. However, they also find that such deviations from the general German wind production do not appear to occur consistently, as "no location is persistently, i.e., in every calendar month of the year, above the average" (p. 1). Schmidt et al. (2013) analyze the covariance between the generation at Austrian sites with overall generation, and find that an MPS leads to a different allocation of turbines.

Other studies have analyzed the consequences of the MPS in terms of financing structures. Gawel and Purkus (2013) raise the concern that the induced additional investment risk might be larger than the benefits from an MPS, since investors do then not only lack perfect foresight with respect to the weather, but also with respect to their compensation per unit of produced electricity. More specifically, Tisdale et al. (2014) analyze the effect that the reliance on project finance for investors has in combination with the MPS. They find that the MPS incurs additional risks to investors, which increases their return on investment requirements for raising debt. In order to have access to such cheap debt, investors are bound to conservative estimates of their future cash flows, as these are the only source from which creditors are paid.

To the author's best knowledge, the impact of the MPS on the technology choice of investors has not been studied so far. Grothe and Müsgens (2013) assume a standard 1.5 MW wind turbine for all locations, which cannot be altered. Similarly, Schmidt et al. (2013) assume a 2 MW turbine across all locations. Yet, different locations require different turbine technologies. Sites with poor wind conditions tend to have other technology configurations installed than sites with favorable conditions. I add to the literature by on the one hand explicitly allowing for different turbine technologies at different sites. On the other hand, I then also allow for these technologies to be altered through exogenous policy changes, so that I can analyze the impact of different policy schemes on investors' technology choices.

The main technology parameters are a turbine's hub height, the generator size, and the rotor blade length. First, a greater hub height incurs higher costs for materials, but as wind strengths increase in greater heights, a turbine receives higher wind speeds. The more obstacles there are on the ground, the more the wind strength increases with additional height. This is one reason why we can observe that wind turbines at the coast tend to be smaller (as they are exposed to the open sea) than turbines in southern Germany. Second, the rotor blade length defines how much energy a turbine can harvest from the wind at any given wind strength. With a longer rotor blade and thus a larger rotor swept area, the turbine is exposed to more wind energy. Third, a larger size of the generator means an increased maximum conversion of wind energy into electricity.

With a greater hub height, a turbine faces more times of medium and high wind speeds. Thus, it is able to generate electricity at more times, and more regularly. Moreover, the ratio of rotor swept area to generator size is the power density, measured in $m^{2} / k W$. In the hypothetical case of a very high power density (large rotor blades with a generator with a low nominal power), turbines 
are almost always be able to capture enough energy from the wind to fuel its generator at full name plate capacity. Thus, such a turbine would have a very high capacity factor and high number of full load hours. Its electricity generation would be very stable and hardly intermittent. Beyond that, it could add to system adequacy with close to its entire capacity.

Vice versa, a turbine with a low power density (short rotor blades and generator with a large nominal power) can hardly ever reap enough energy from the wind to run its generator at full capacity. With every small change in wind speeds, the amount of generated electricity changes, as the generator is operating below its maximum. At low wind speeds, only little electricity can be produced, as the short rotor blades are not able to harvest a lot of energy. Thus, such a technology configuration produces highly intermittently, and could hardly add to system adequacy. Accordingly, turbines with a higher power density are considered more system-friendly, as they produce at higher market value and require less back-up capacity, storage, grid extension and demand-side responses. These benefits need to be balanced with the higher costs per MWh electricity produced from system-friendly turbines.

In the last years, the power density in Germany has already increased slightly (Deutsche WindGuard, 2015). However, this appears to be mostly driven by the emergence of turbines with higher power densities in southern Germany. There is no clear evidence that turbine technologies in the north/north-east have changed in the meantime (Fraunhofer IWES, 2013b). Among others, Deutsche WindGuard (2014), Molly (2011, 2012, 2014), Fraunhofer IWES (2013a), Fraunhofer IWES (2013b) and Hirth (2015) argue that turbines with higher power densities than the current standard would benefit the energy system as a whole and lead to lower overall costs. This is achieved due to increased market values and a smoother electricity feed-in, requiring less other flexibility options like storage, grid extension and demand side responses.

The question remains what turbine designs investors opt for under different policy regimes, and how valuable such configurations are for the system ${ }^{2}$. These are some of the main questions addressed in this paper: (How) does the introduction of the floating market premium scheme effect investors' technology choice? How effective are alternative policy measures in incentivizing the deployment of more system-friendly wind turbines?

Knowing about the effects on risk and locational choices, this study contributes to the literature since it is the first of its kind to scrutinize the effect of the MPS on investors' technology choices, and the channels through which such effects could be induced. In particular, I analyze how project finance-related constraints and imperfect foresight influence investors' decisions. Moreover, I look at an additional change in the production volume-based benchmark approach (German: Referenzertragsmodell), which underlies both the FIT and the MPS. Its basic intention was to provide a cost-covering remuneration scheme that adjusts the average level of remuneration depending on the wind resources of a site. Thus, locations with poorer wind conditions become more attractive to wind projectors than with a uniform remuneration level, so that not all turbines are clustered at the high-wind spots at the coast. This model has been part of the German renewable support scheme since 2000 and is one of its elements that has

\footnotetext{
${ }^{2}$ As Joskow (2011) points out, it is not sufficient to merely compare the Levelized Cost of Electricity and opt for the volatile technology that comes at the least costs per $\mathrm{kWh}$ because the production values can vary.
} 
not been altered since. Yet, as suggested by Deutsche WindGuard (2014), this differentiation between locations in its current form potentially favors turbines with lower power densities and can be utilized to render system-friendly turbines more attractive. This study identifies the channels through which such a change in the production volume-based benchmark approach impacts investors' technology decisions.

Furthermore, I suggest and model a production value-based benchmark approach that explicitly accounts for imperfect foresight of the investors with respect to the future electricity price profile (i.e. a trend towards even lower prices in times of high wind speeds, and relatively higher prices during low and medium wind speeds) and investors' reliance on access to risk-averse debt. It replicates the cost-covering nature of the production volume-based benchmark approach (where remuneration is adjusted to the location) and applies it to the turbine configuration and thus system-friendliness of turbines: Based on a model of the future energy system, it a-priori adjusts a turbine's remuneration level depending on its system-friendliness. Investors fully receive the average production value their turbines will provide in the future. Thus, turbines that in the future provide a greater system value - here narrowly defined as market value - are eligible to a higher remuneration level. This way, the system-optimal turbine (minimizing the subsidy level by minimizing the annuitized cost per MWh minus value per MWh) is also most attractive to investors. ${ }^{3}$

The remainder of this paper is structured as follows: in section 2, I give an overview of the calculations for the fixed FIT, the MPS, the production volume-based benchmark approach including its analyzed adjustment, and the production value-based benchmark approach. Simultaneously, I present the investment model. Next I briefly describe the data in section 3 . In section 4 come the results. Section 5 draws a conclusion and indicates policy implications.

\section{Methodology}

For the analysis, I model wind investors' investment decisions. They optimize their discounted future revenues and costs and take the prevailing renewable support scheme as exogenously given. I analyze one scenario per support scheme, and investigate the differences between these. I outline the fixed FIT and the MPS in sections 2.1 and 2.2 and how they have been implemented in the investment decision model. Next, in section 2.3 , I characterize the production volumebased benchmark approach, and how a change in its definition potentially favors more system-friendly wind turbines. Finally, the production value-based benchmark approach is a policy explicitly granting remuneration depending on the turbine's future system-friendliness, as laid out in section 2.4.

\subsection{Fixed feed-in tariff}

Fixed feed-in tariffs compensate investors with a fixed payment per generated $\mathrm{kWh}$. It is fixed, but a turbine receives either the initial high payment or a lower, subsequent payment, depending on its production. Thus,

\footnotetext{
${ }^{3}$ Öko Institut (2014) suggest a different remuneration scheme where the remuneration is dependent on a turbine's production characteristics in order to support system-friendly turbines.
} 


$$
\begin{aligned}
\pi_{F I T_{i, t, h}} & =F I T_{i, t, h} \\
& =F I T_{\text {high }} \chi_{i, t}+F I T_{\text {low }}\left(1-\chi_{i, t}\right)
\end{aligned}
$$

where $\pi_{F I T_{i, t, h}}$ is the payment per $\mathrm{kWh}$ at hour $h$ of year $t$ for turbine $i$ and it is simply equal to the FIT. $F I T_{i, t, h}$ depends on time since turbines are eligible to the higher initial FIT for different lengths of periods. All investors receive an initial, higher $F I T_{\text {high }}$ for a certain period, and a lower subsequent $F I T_{\text {low }}$ until 20 years after installation. The initial period lasts at least 5 years, and can be extended to cover up to the whole 20 year period. For exactly how long it is extended depends on the location and technology chosen, cp. section 2.3. The variable $\chi_{i, t}$ lies between 0 and 1 . It reflects that in any hour $h$ of any year $t$, a turbine receives either the high initial FIT $F I T_{\text {high }}$ or the lower subsequent FIT FIT $T_{\text {low }}$. Such a fixed FIT is regarded as effective and efficient in promoting renewable energies (Butler and Neuhoff, 2008). Many other countries have introduced it as well, 98 by 2013 (REN21, 2014).

The fixed FIT is the baseline scenario. For investors, it is exogenous and they optimize the Net Present Value (NPV) of their wind turbine investment for an expected lifetime of 20 years. Discounting future revenues by the discount factor $\delta$, under the FIT, the NPV is calculated by

$$
N P V_{F I T_{i}}=-f c_{i}+\sum_{t=1}^{t=20}\left(\sum_{h=1}^{h=8760} \delta^{t} \omega_{i, t, h}\left(\pi_{F I T_{i, t, h}}-v c_{t}\right)\right)
$$

The turbines $i$ are characterized by individual configurations of hub height, generator size and rotor blade length. $f c_{i}$ represent the fixed costs of turbine $i$. To mirror the trade-off between these components, however, I consider only turbines with the same overall prices. They range between rather system-friendly (high power density and high hub height) and less system-friendly (low power densities and lower hub height). For every year $t$, it is summed over every hour of the year $h^{4}$. The amount of generated electricity is captured in $\omega_{i, t, h} . v c_{t}$ are the variable operation and maintenance costs. Following Deutsche WindGuard (2013), they are $24.1 € / M W h$ for the first ten operational years, and $26.8 € /$ MWh afterwards.

In this analysis, I concentrate on the investment decision for a single turbine. The investor optimizes with respect to the choice of the turbine technology $i$. Thus, the investor's optimization reads as

$$
\begin{gathered}
\max _{\mu} N P V_{F I T}=\sum_{i=1}^{i=N} \mu_{i} N P V_{F I T_{i}} \\
\text { s.t. } \sum_{i=1}^{i=N} \mu_{i}=1
\end{gathered}
$$

which is simply the sum of all $N$ turbine $i$ 's NPVs, each multiplied with $\mu_{i}$, a binary variable indicating which turbine an investor chooses. Following Schmidt

\footnotetext{
${ }^{4}$ It is summed over all hours of the year, 8760 in normal years. For a sensitivity analysis using data from the gap year 2012 the last day of the year is cut off.
} 
et al. (2013), treating $\omega_{i, t, h}$ as a random variable, it is possible to express the investor's expected NPV as in figure 6 .

$$
E\left(N P V_{F I T}\right)=\sum_{i=1}^{i=N} \mu_{i}\left(-f c_{i}+\sum_{t=1}^{t=20}\left(\delta^{t} \sum_{h=1}^{h=8760} E\left(\omega_{i, t, h}\right)\left(E\left(\pi_{F I T_{i, t, h}}\right)-v c_{t}\right)\right)\right)
$$

For this to hold, I assume that the covariance between $\omega_{i, t, h}$ and $\pi_{F I T_{i, t, h}}$ is zero. This implies that investors choose to maximize output under a fixed FIT, as assumed in Schmidt et al. (2013), and Deutsche WindGuard (2014).

\section{$2.2 \quad$ Floating Market premium scheme}

According to the German law, the payment received for a generated $\mathrm{kWh}$ from wind power is calculated as follows (Bundestag, 2014):

$$
\pi_{M P S_{i, t, h}}=p\left(\omega_{-i, t, h}\right)+\left[F I T_{h i g h} \chi_{i, t}+F I T_{\text {low }}\left(1-\chi_{i, t}\right)-\psi_{\text {month }} \bar{p}_{\text {month }}\right]
$$

where $\pi_{M P S_{i, t, h}}$ represents the payment for one $\mathrm{kWh}$ of generated electricity by turbine $i$ at hour $h$ of year $t . p\left(\omega_{-i, t, h}\right)$ is the electricity price, assuming that the single investor's investment decision and thus the turbine's power output does not have an impact on electricity prices. However, the cumulative output of all German wind turbines $-i$ depresses electricity prices, the merit-order effect, e.g. discussed in Cludius et al. (2014), Würzburg et al. (2013), Sensfußet al. (2008) and Hirth (2013). FIT high are again the initially higher and subsequently lower payments turbines receive ${ }^{5}, \chi_{i, t}$ is a factor between zero and one determining which FIT a turbine is eligible to, $\psi_{\text {month }}$ a month-specific wind-value adjustment factor, and finally $\bar{p}_{\text {month }}$ the average price at which electricity was sold in a month.

$$
M P_{i, h, t}=F I T_{\text {high }} \chi_{i, t}+F I T_{\text {low }}\left(1-\chi_{i, t}\right)-\psi_{\text {month }} \bar{p}_{\text {month }}
$$

$M P_{i, h, t}$ is the so-called market premium. It is equal to the FIT minus the average German electricity wholesale day-ahead market price times a monthspecific wind-value adjustment factor. In any month, if German wind power was sold at 90 percent of the average market price, this adjustment factor would be equal to 0.9. A turbine that produces perfectly correlated with the overall German wind generation receives exactly the feed-in payment, the first and last term of the payment-formula cancel each other out.

If a turbine is able to produce rather in times of generally lower German wind feed-in (and thus under ceteris paribus higher electricity prices), it receives a surplus over the feed-in payment. Conversely, a turbine that produces primarily when the German wind power generation is high (and thus prices are lower) will earn less than the feed-in payment. An obvious and intended consequence of the MPS is that turbine operators have an incentive to stop operating in times where their overall payment per $\mathrm{kWh}$ is negative. This is the case when the

\footnotetext{
${ }^{5}$ This is almost the same amount as the previous values for a pure fixed FIT. However, since the law's revision in 2014, it is additionally intended to capture the extra management costs of direct marketing, and was thus increased slightly.
} 
electricity price is negative and its absolute value is larger than the market premium.

As argued in section 1, the location can potentially determine whether a turbine is able to deviate from the national wind power production. Additionally, the technology configuration might be able to influence this correlation. After all, the goal of the MPS' introduction was to give investors incentives to heed more to market signals. An example illustrates the potential mechanism: The German wind power production is driven by turbines installed in northern Germany. Moreover, the turbines installed there have on average power densities of around $2.5 \mathrm{~m}^{2} / \mathrm{kW}$ (Deutsche WindGuard, 2015). This implies that they are rather proficient at reaping higher wind speeds, and not so at lower speeds. Thus, at lower wind speeds in northern Germany, wind power generation is relatively low and ceteris paribus electricity prices are rather high. If then a turbine with a rather high power density was installed in northern Germany, it could produce a larger share of electricity in times of low wind speeds, and benefit from the higher prices. It would produce relatively less electricity in times of high wind speeds in northern Germany, but as prices tended to be lower then, it could be economical overall to opt for the turbine with a higher power density.

In the MPS case, the NPV of every turbine technology $i$ is

$$
N P V_{M P S_{i}}=-f c_{i}+\sum_{t=1}^{t=20}\left(\delta^{t} \sum_{h=1}^{h=8760} \omega_{i, t, h}\left(\pi_{M P S_{i, t, h}}-v c_{t}\right)\right)
$$

The investor optimizes

$$
\begin{gathered}
\max _{\mu} N P V_{M P S}=\sum_{i=1}^{i=N} \mu_{i} N P V_{M P S_{i}} \\
\text { s.t. } \sum_{i=1}^{i=N} \mu_{i}=1
\end{gathered}
$$

Again following Schmidt et al. (2013), I take expectations of the NPV. For simplicity, I apply them to equation 9, the NPVs of single turbines, rather than the overall optimization problem in equation 10:

$$
\begin{gathered}
E\left(N P V_{M P S_{i}}\right)=-f c_{i}+\sum_{t=1}^{t=20}\left(\sum_{h=1}^{h=8760} \delta^{t} E\left(\omega_{i, t, h}\left(\pi_{M P S_{i, t, h}}-v c_{t}\right)\right)\right) \\
E\left(N P V_{M P S_{i}}\right)=-f c_{i}+\sum_{t=1}^{t=20}\left(\delta ^ { t } \sum _ { h = 1 } ^ { h = 8 7 6 0 } \left(E\left(\omega_{i, t, h}\right) E\left(\pi_{M P S_{i, t, h}}\right)\right.\right. \\
\left.\left.+\operatorname{Cov}\left(\omega_{i, t, h}, \pi_{M P S_{i, t, h}}\right)-E\left(\omega_{i, t, h}\right) v c_{t}\right)\right)
\end{gathered}
$$

Combining equation 7, equation 8 and equation 13 yields 


$$
\begin{aligned}
E\left(N P V_{M P S_{i}}\right)= & -f c_{i}+\sum_{t=1}^{t=20}\left(\delta ^ { t } \sum _ { h = 1 } ^ { h = 8 7 6 0 } \left(E\left(\omega_{i, t, h}\right)\left(E\left(p\left(\omega_{-i, t, h}\right)\right)+M P_{i, t, h}\right)\right.\right. \\
& \left.\left.+\operatorname{Cov}\left(\omega_{i, t, h}, p\left(\omega_{-i, t, h}\right)\right)+\operatorname{Cov}\left(\omega_{i, t, h}, M P_{i, t, h}\right)-E\left(\omega_{i, t, h}\right) v c_{t}\right)\right)
\end{aligned}
$$

Regardless of the absolute merit-order effect, when assuming a linear negative functional form $p\left(\omega_{-i, t, h}\right)=p^{*}-a \omega_{-i, t, h}$ (with $p^{*}$ as reference price without any wind power supply and $a$ as a positive scalar) for the price depending on German wind power generation, this can be rewritten as ${ }^{6}$

$$
\begin{aligned}
E\left(N P V_{M P S_{i}}\right)= & -f c_{i}+\sum_{t=1}^{t=20}\left(\delta ^ { t } \sum _ { h = 1 } ^ { h = 8 7 6 0 } \left(E\left(\omega_{i, t, h}\right)\left(E\left(p^{*}-a \omega_{-i, t, h}\right)+M P_{i, t, h}\right)\right.\right. \\
& \left.\left.-a \operatorname{Cov}\left(\omega_{i, t, h}, \omega_{-i, t, h}\right)+\operatorname{Cov}\left(\omega_{i, t, h}, M P_{i, t, h}\right)-E\left(\omega_{i, t, h}\right) v c_{t}\right)\right)
\end{aligned}
$$

This equation shows that the expected NPV of a turbine technology $i$ decreases the larger the covariance between a turbine's generation $\omega_{i, t, h}$ and the overall German wind power supply $\omega_{-i, t, h}$. Stated positively, a turbine technology is more attractive to investors, the lower the covariance of its electricity generation and the German wind power supply.

\subsection{Production volume-based benchmark approach}

The production volume-based benchmark approach aims to diversify the installation locations of German wind turbines. At a broad range of locations, it provides cost-covering remuneration. Without it, investors would - even stronger than observed - prefer only those sites with the most favorable wind conditions, largely in the North at the German coast. The production volume-based benchmark approach increases the attractiveness also of sites with poorer wind conditions. This has the advantage from the system's perspective that the supply of electricity is to a smaller extent locally concentrated in one area, and less infrastructure is required for grid integration. The more decentralized wind production also implies that turbines in different locations may face differing wind patterns, reducing peak production and delivering smoother power supply from wind turbines.

As such local diversification has been and is still desired, the production volume-based benchmark approach has been part of the fixed FIT and prevails in the MPS. Figure 1 illustrates for one turbine what average remuneration level investors are eligible to at different locations. The cost curve is of a purely illustrative nature, scaled to equal the remuneration for a turbine that reaches 80 percent of full load hours as compared to the benchmark location, as explained in the following. For this purpose, the costs per $\mathrm{kWh}$ are assumed to be only

\footnotetext{
${ }^{6}$ For simplicity, assuming that $\operatorname{Cov}\left(\omega_{i, t, h}, p^{*}\right)=0$.
} 


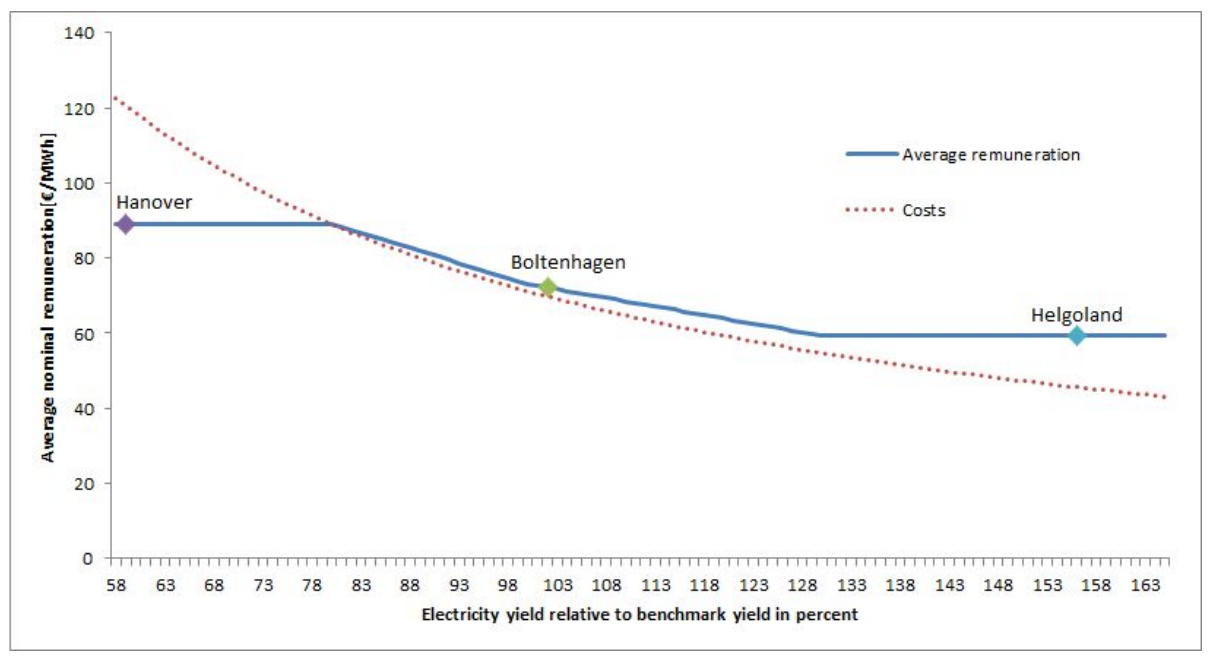

Figure 1: Average remuneration at different locations

dependent on the amount of energy produced at a site. It is evident that investments in a wind-rich location as Helgoland require a lower feed-in tariff than investments in sites with poor wind strengths such as Hanover.

However, with the remarkable exception of Deutsche WindGuard (2014), it has not been considered to what extent the production volume-based benchmark approach also impacts the technology choice of investors.

For every turbine type, its theoretical production at a defined benchmark location is calculated. This definition has not been altered since 2000 and is (Bundestag, 2014): The wind at the benchmark location follows a Weibull distribution with a shape parameter of $\alpha=2$ (which makes it a Rayleigh distribution), with an average wind speed of $5.5 \frac{\mathrm{m}}{\mathrm{s}}$ at a height of $30 \mathrm{~m}$. Vertical extrapolation functions through a logarithmic height profile. Its roughness length $z_{0}$ is 0.1 . In accordance with legislation, every wind turbine type is theoretically installed at this benchmark location, and the annual benchmark yield is calculated. The actual electricity yield where a wind turbine is installed, $\omega_{i, t, h}$, is then set in relation to this benchmark yield, which gives the benchmark ratio $\zeta_{i}$. The lower this benchmark ratio is, the longer a wind investor receives the higher feed-in payment.

The exact remuneration depends on the benchmark ratio and has changed over time. In its current form, the calculation of the length extension $l$, measured in months after installation, adheres to:

$$
l_{i}= \begin{cases}60 & \text { if } \zeta_{i} \geq 130 \%, \\ 60+\frac{130-\zeta_{i}}{0.36} & \text { if } 130 \% \geq \zeta_{i} \geq 100 \%, \\ 60+\frac{130-\zeta_{i}}{0.36}+\frac{100-\zeta_{i}}{0.48} & \text { if } 100 \% \geq \zeta_{i} \geq 80 \%, \\ 240 & \text { if } \zeta_{i} \leq 80 .\end{cases}
$$

Naturally, investors prefer receiving the longer feed-in payment for an extended period, so that this formulation renders sites with poorer wind conditions 
more attractive to them and compensates for some of the reduced energy output. This same mechanism leads to a non-neutral treatment of different technologies. To illustrate this, I assume an investor decides between two turbines. In order to compare roughly comparable turbines, I assume them to have the same prices. The first turbine $i_{1}$ has a very low power density (less system-friendly), and the second turbine $i_{2}$ a higher power density (more system-friendly). Consequently, compared to turbine $i_{2}$, turbine $i_{1}$ is better at harvesting wind energy at high speeds, and worse at lower wind speeds.

Turbine $i_{1}$ produces a total amount of $e_{1} \mathrm{kWh}$ over its initial five years of operation and has a benchmark yield of by $y_{1}$. Its benchmark ratio is $\zeta_{1}$, resulting in a length extension $l_{1}$. Similarly, turbine $i_{2}$ receives a length extension $l_{2}$.

If we were to increase the weight of lower wind speeds at the benchmark location, and to correspondingly decrease the weight of higher wind speeds at the benchmark location, those values would change. As turbine $i_{2}$ has a low power density, it is - relative to turbine $i_{1}$ - better at harvesting the wind energy at the lower wind speeds, so that its benchmark yield by $y_{2}$ relatively increases. As its real production stays the same, its benchmark ratio relatively decreases. Last but not least, this means that its length extension $l_{2}$ grows relatively more than $l_{1}$. Thus, the more system-friendly turbine $i_{2}$ becomes more attractive to investors.

Such an increased weight on lower wind speeds is achieved through a decrease in the mean wind speed at the benchmark location. To scrutinize the described effect on technology choice, I model a change in the mean wind speed from $5.5 \mathrm{~m} / \mathrm{s}$ to $5.0 \mathrm{~m} / \mathrm{s}$, as suggested by Deutsche WindGuard $(2014)^{7}$.

Figure 2 visualizes the difference between the default and adjusted benchmark locations ${ }^{8}$. At the default location, stronger winds have more weight, they occur more often. In contrast, the adjusted benchmark location values the low-to-medium wind speeds higher, their probability is larger.

\subsection{Production value-based benchmark approach}

Without perfect foresight, investors might expect the current power price profile to roughly continue in the future. Thus, they underestimate the rising profitability of system-friendly turbines that comes with a shift in the electricity price profile, i.e. relatively higher prices in times of high wind speeds and relatively lower prices during weaker and medium wind speeds. Even with perfect foresight, investors are constrained by their financing through project finance. Thus, they might be bound to conservative assumptions on future price profile developments (Tisdale et al., 2014), again underestimating the future value of system-friendly turbines.

Figure 3 indicates stylized what consequence such an over-valuation of the current electricity price profile leads to. In this example, from a cost-minimizing perspective, a turbine with a power density around $2.75 \mathrm{~m}^{2} / \mathrm{kW}$ minimizes the annuitized costs per MWh, as encouraged by the FIT. However, this disregards

\footnotetext{
${ }^{7}$ This adjustment requires the remuneration thresholds in equation 16 to vary accordingly, from 130 percent to 162.5 percent, from 100 percent to 125 percent, and from 80 percent to 109.4 percent.

${ }^{8}$ These are the probability density functions of two Weibull distributions with shape parameters $\alpha=2$ and scale parameters $\beta=6.21$ (default) and $\beta=5.64$ (adjusted), based on the distribution means.
} 


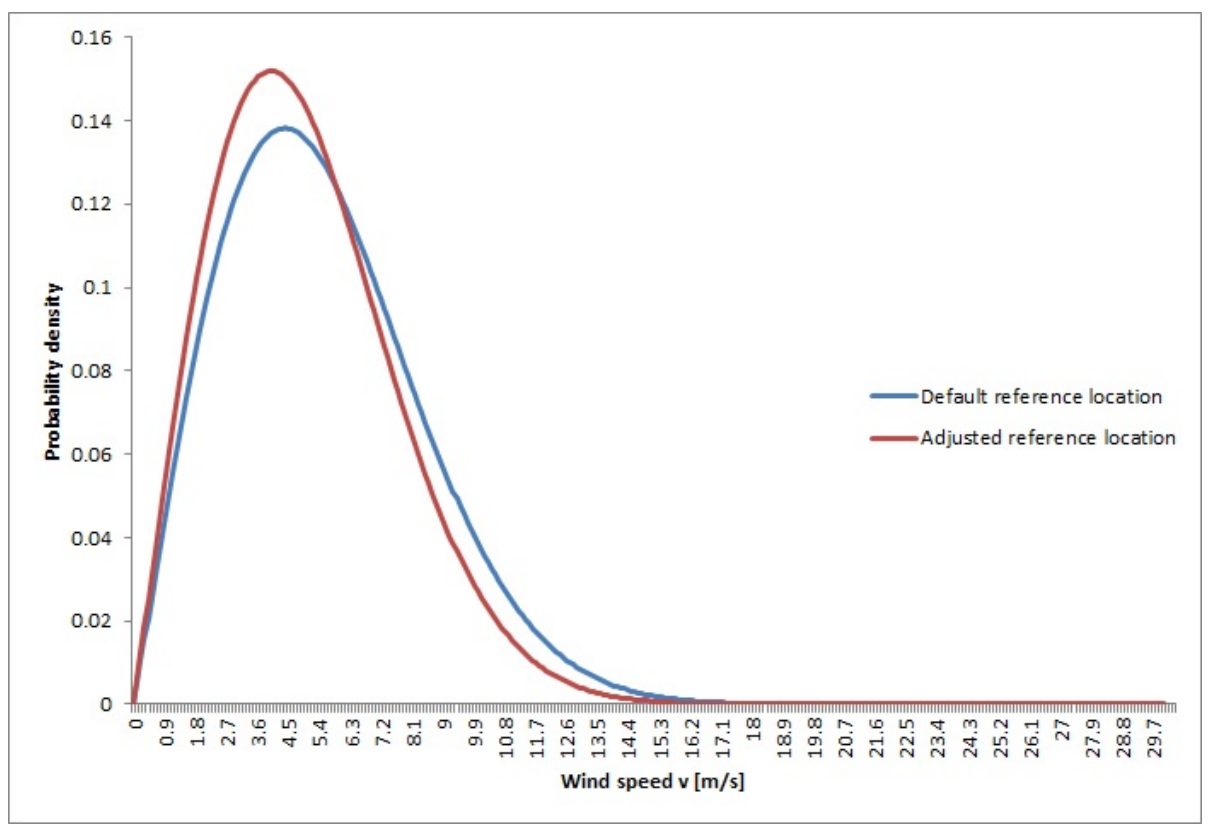

Figure 2: Distribution of wind speeds at benchmark locations

the market value of the production. Looking at today's power system, a turbine is system-optimal if the slope of the average market value today is parallel to the annuitized cost curve, i.e. average costs are equal to (the slope of) average prices $^{9}$. The increase in average costs compared to the cost-minimizing turbine is over-compensated by the increase in average production value. In the future, with a more pronounced power price profile, the slope of the average price obtained by the different turbines will be steeper. As a consequence, the slope of the future average price and the cost curve are parallel for a turbine with a higher power density. An over-valuation of today's power price profile means that in the future, the turbines have a too low power density, they are not system-friendly enough as compared to the system-optimum.

The system-optimum thus depends on the time horizon chosen to consider. As in the German support scheme, a lifetime of 20 years is usually assumed. Moreover, the discount rate matters. Lower, social discount rates lead to stronger valuations of the future and therefore system-optima that are more system-friendly. Depending on these parameters, the system-optimal turbine for new installations lies further right or left in figure 3. Here, I abstract from the discussion which period to consider and what discount rate to apply. I simplify by assuming that solely the energy system of 2030 defines the system optimal turbine.

As laid out in the introduction, changes in the power price profile are expected under further-increasing renewable energy penetration, as among others identified by Hirth (2013) and Ueckerdt et al. (2013) ${ }^{10}$, and investors have lim-

\footnotetext{
${ }^{9}$ Unless in a system where renewable energies can entirely re-finance themselves via the energy-only market, the average market value will lie below the cost curve. Hence, only slopes can be compared, and not absolute values.

${ }^{10}$ In the German context, the nuclear phase out adds to this effect with less base load
} 


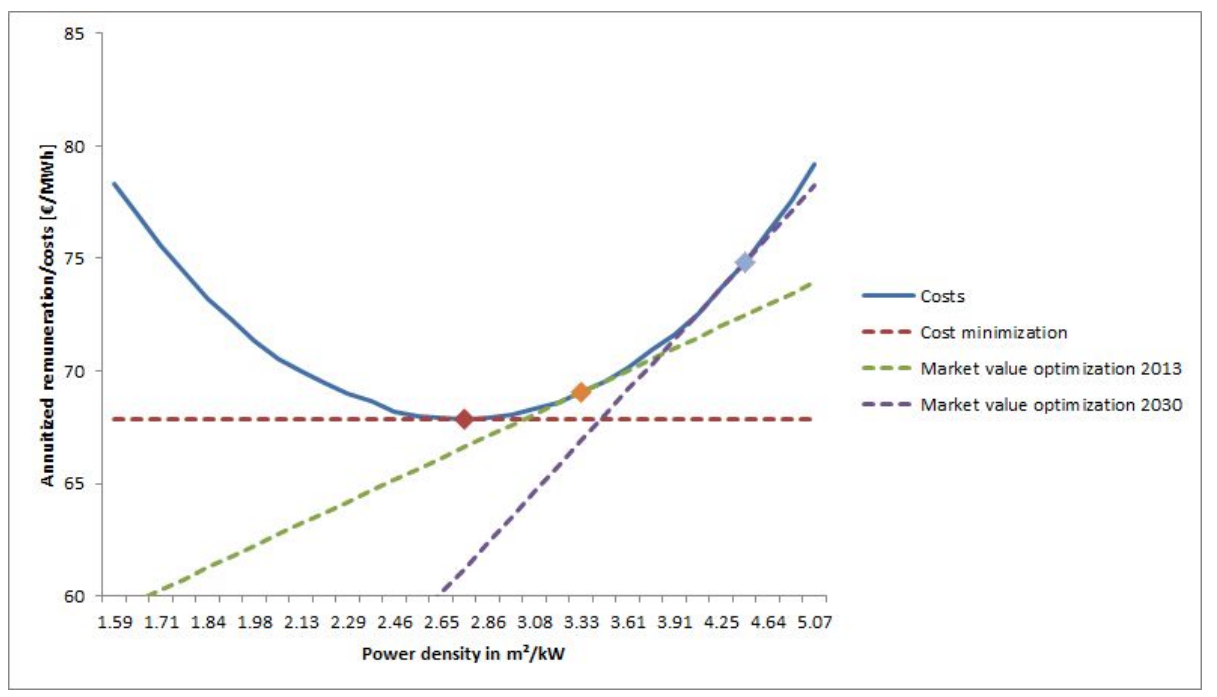

Figure 3: Illustrative visualization of system optimal turbines from different perspectives

ited foresight and suffer from financing constraints. Consequently, in order for investors to be able to consider these future developments independent of their own expectations and financing constraints, the future value of different turbine technologies can be directly reflected in the remuneration levels these turbines are eligible to. In the following, one potential way how this can be achieved is implemented, based on a future energy model described in section 3.1. It is analogous to the production volume-based benchmark model: There, based on a benchmark location, the (duration of the higher initial) remuneration is adjusted so that the total remuneration is dependent on the location. Analogously, using a benchmark turbine, the remuneration can be adjusted based on the turbine configuration.

The remuneration level - implemented based on the fixed feed-in tariff and the default benchmark location definition, cp. section 2.3 - is adjusted dependent on a turbine's future production value. The remuneration level under the FIT, $F I T_{\text {high }} / F I T_{\text {low }}$ is individualized, $F I T_{\text {high }_{i}} / F I T_{\text {lowi }_{i}}$, to any turbine's production characteristics: Turbines that provide a higher value to the system, measured as the average electricity price they obtain in 2030, receive a higher remuneration level than other turbines. In order to ensure that the turbine $\lambda$ that is privately optimal under the FIT can be taken with the same remuneration level also under the production value-based benchmark approach, the remuneration level is calibrated such that this is the case. Hence, for this calibration, the turbine $\lambda$ that is privately optimal under the FIT needs to be identified and used as reference for the scaling.

Combining the future electricity prices that are based on wind speeds in a baseline year, wind speed data at the analyzed site from that baseline year, and any turbine's power curve, it is possible to calculate the average price a turbine will obtain in 2030, $\bar{p}_{2030_{i}}$. For any turbine $i$, the average production value

generation at a low marginal cost. 


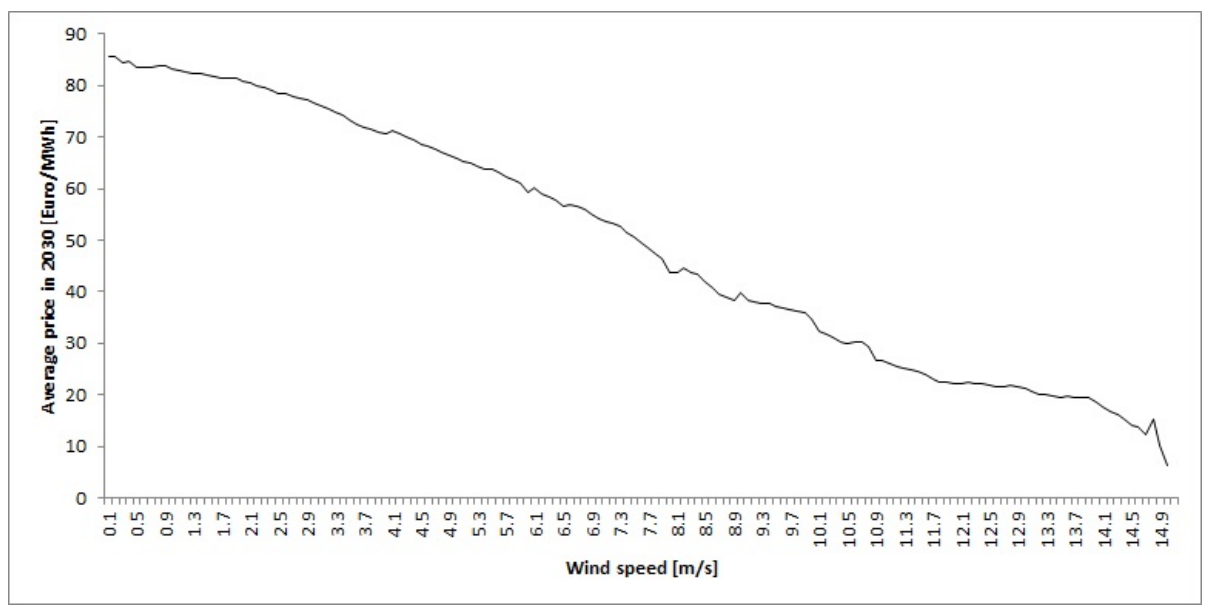

Figure 4: Moving average of the electricity price in 2030

in 2030 of turbine $\lambda, \bar{p}_{2030_{\lambda}}$, is subtracted from the baseline $F I T_{\text {high }} / F I T_{\text {low }}$. Then, the average production value in 2030 of that turbine $i, \bar{p}_{2030_{i}}$, is added, as shown in equations 17 and 18 .

$$
\begin{gathered}
F I T_{\text {high }_{i}}=F I T_{\text {high }}-\bar{p}_{2030_{\lambda}}+\bar{p}_{2030_{i}} \\
F_{I T_{\text {low }_{i}}}=F I T_{\text {low }}-\bar{p}_{2030_{\lambda}}+\bar{p}_{2030_{i}}
\end{gathered}
$$

Consequently, if a turbine's average production value $\bar{p}_{2030_{i}}$ lies above $\bar{p}_{2030_{\lambda}}$, this turbine will receive a higher remuneration per MWh. By design, the increase in remuneration level $F I T_{h i g h_{i}}-F I T_{h i g h_{\lambda}}$ is exactly equal to the increase in average value $\bar{p}_{2030_{i}}-\bar{p}_{2030_{\lambda}}$. In other words, the increase in value makes up for any increase in costs for the system.

Very generally, more system-friendly turbines tend to produce at a higher average future production value $\bar{p}_{2030}$, and at a higher cost per MWh. An investor will choose an increasingly more system-friendly turbine as long as the increase in remuneration per MWh offsets the increase in costs per MWh. Thus, the system-optimal and equally privately-optimal turbine is identified. For example, the maximum spread in average value and thus the production value-based benchmark approach remuneration per MWh between the two most extreme turbine configurations lies at 6.9 Euros/MWh by 2030 at a site with intermediate conditions.

Figure 4 shows the expected pattern: in the future energy system, the value of electricity deteriorates in times of strong wind speeds, and is highest during weak winds. Depicted are the location Boltenhagen and its wind speeds at $80 \mathrm{~m}$.

The advantage of this approach is that $\bar{p}_{2030_{i}}$ is only dependent on value to the system, but is wind-technology-, time- and production-independent. Hence, it can be computed in advance, so that no additional risks during the turbine's lifetime are incurred. A limitation is that the investor requires data on the frequency of wind speeds from the baseline year at the analyzed location(s) in 
advance that are reliable enough to calculate $\bar{p}_{2030_{i}}$ from it. If no reliable enough wind atlas was available, an alternative option could be the use of average wind speeds at nearby measuring points. Moreover, the regulator needs to provide a forecast for the future power price profile. While such projections are inherently uncertain, e.g. linked to fuel and carbon price assumptions, not the absolute level, but only variations from average price are relevant. The most relevant uncertainties link to shares of renewables, grid and storage development and are thus largely determined by public policy choices. As such, the commitment of a regulator to a specific 2030 perspective, for example with the power price profile forecast, is the basis for coordinating private actor choices. Assuming that future electricity prices differ between hours with high and low amounts of wind power seems reasonable to expect and is in line with Hirth (2013) and Ueckerdt et al. (2013).

\section{Data}

I utilize three kinds of data sets: past day-ahead electricity prices, modeled spot market prices in future energy systems, and empirical data on wind strengths at different locations. Unlike most other models in the literature, I do not use a fixed number of real turbines and their respective power curves, but apply a scaling model for modeling power curves based on technology parameters, as explained in section 3.2. As investors face a trade-off between different technology parameters, section 3.3 describes this trade-off. Measured wind speeds are extrapolated to actual hub heights, described in section 3.4.

\subsection{Market prices}

The day-ahead market prices for the year 2013 (and 2012) are obtained from European Energy Exchange (2015). In 2012, there were 56 hours with negative prices, and an average negative price of $-60.51 €$. In 2013, there were slightly more hours with negative prices, 64 in total, but with a considerably less-negative average price of $-14.17 €($ Agora Energiewende, 2015). The model is implemented with a discount factor of $\delta=0.95$.

The underlying model REMix estimating electricity prices in 2030 was developed by Deutsches Zentrum für Luft-und Raumfahrt (2014) in order to evaluate the long-term developments of power plants, the grid, demand side management, energy storage and combined heat and power. It assumes a minimum share of renewable energies of 50 percent of the total electricity generation by 2030 . Investments are endogenous and take place at the sites with the best wind resources first. The modeled years are based on the wind speed patterns of 2006 . The electricity prices indicate the value of power generation in future energy systems with higher shares of renewables. Looking at the price estimates, one can observe that the overall price level will increase. Moreover, the price variation increases, possibly due to the further-increasing share of fluctuating renewable energies. The results have been verified with a scenario with endogenous, optimized grid investments. As can be expected, price variation and thus the case for system-friendly turbine designs decreases, but only slightly so. For instance for Boltenhagen, the system-optimal turbine's power density is decreased by .14 $m^{2} / k W$ or 4 percent. For a wind-rich location as Helgoland, the system-optimal 
turbine actually has an even slightly higher power density. Deutsches Zentrum für Luft-und Raumfahrt (2014) provides a detailed explanation of the model.

\subsection{Power curve scaling}

A turbine's electricity output crucially hinges on its power curve. A power curve describes how efficiently a turbine converts energy from wind into electricity. It does so depending on two factors: Firstly, its generator size sets how much electricity it can produce maximally. Secondly, the length of its rotor blades specifies how much energy it can potentially extract from the wind. This way, investors can optimize over generator size, rotor blade length and hub height. In the model, they can choose without constraint from any power density, measured in $m^{2} / k W$. Based on Narbel et al. (2014), the general formula for the potentially generated electricity $P_{P o t}$ is spelled out in equation 19.

$$
P_{\text {Pot }}=\frac{1}{2} \varphi_{a i r} \pi C_{p} r^{2} v^{3}
$$

$\varphi_{\text {air }}$ is the air density (assumed to be $1.225 \mathrm{~kg} / \mathrm{m}^{3}$ ). $C_{p}$ is the mechanical efficiency. According to Betz' law, it cannot possibly exceed about 59 percent (Narbel et al., 2014). In modern turbines, factors of up 45-52 percent can be observed, e.g. in Enercon $(2012)^{11}$. Lastly, the wind speed $v$ enters the formula in its cubic form, demonstrating the importance of favorable wind conditions for wind power generation.

Furthermore, the generator size has to be considered. Once the nominal power $P_{N o m}$ is reached, the actually produced amount of electricity $P_{W}$ ceases to increase and stays at this maximum until reaching its cut-off speed at around $25 \frac{\mathrm{m}}{\mathrm{s}}$. Close to reaching its nominal power, however, a turbine's mechanical efficiency decreases, resulting in a characteristic dent in the power curve ${ }^{12}$. Besides, turbines also posses cut-in speeds below which they do not start running. I assume these to be lie uniformly at $3 \frac{\mathrm{m}}{\mathrm{s}}$. Equation 20 shows the calculations of the amount of electricity produced at different wind speeds, $P_{W}$.

$$
P_{W}= \begin{cases}0 & \text { if } v \leq 3 \frac{m}{s} \\ P_{P o t} & \text { if } v \geq 3 \frac{m}{s} \text { and } P_{P o t} \leq 0.85 * P_{N o m} \\ \frac{P_{\text {Nom }}-P_{P o t}}{2}+0.85 * P_{N o m} & \text { if } 1.15 * P_{\text {Nom }} \geq P_{P o t} \geq 0.85 * P_{\text {Nom }} \\ P_{\text {Nom }} & \text { if } P_{P o t} \geq 1.15 * P_{\text {Nom }}\end{cases}
$$

In the model, I have implemented the dynamic calculation of power curves based on the underlying technology parameters. This way, the model is flexible to accommodate for investment decisions not only between a few real-world turbines and their respective power curves, but to make that technology-choice close to continuous.

\footnotetext{
${ }^{11}$ In line with Enercon (2012), I assume the maximal mechanical efficiency to decrease from 52 percent for the turbines with the largest generators down to 45 percent for smaller generator sizes.

${ }^{12}$ Here, I used a decrease in efficiency starting at 85 percent of the rated output, approximated from Enercon (2012). The results are robust to sensitivity analyses with respect to the exact specification.
} 


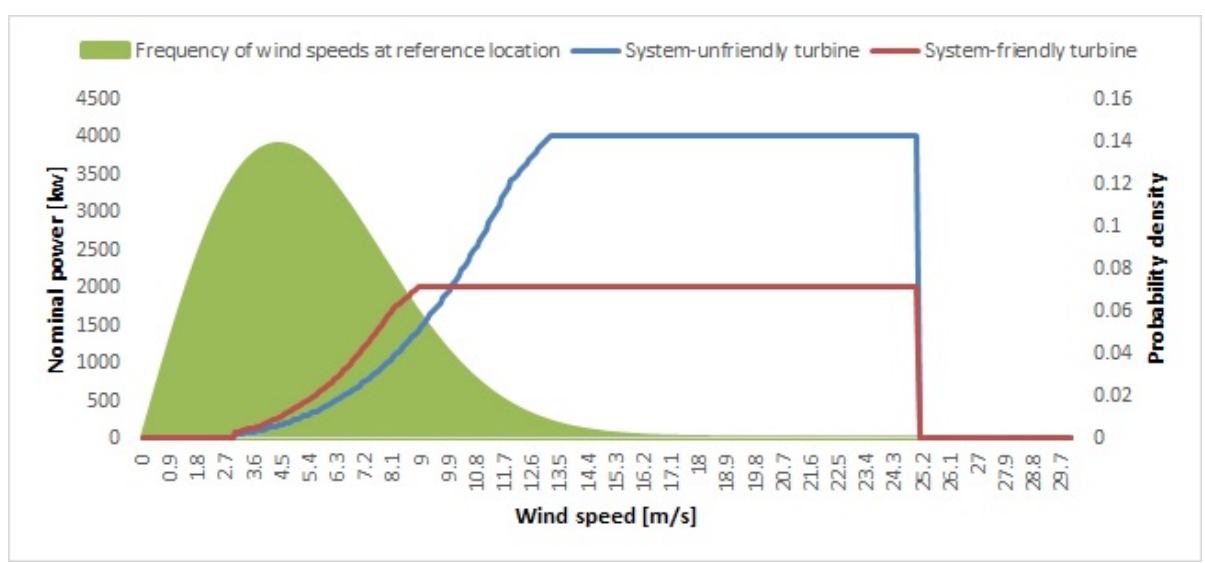

Figure 5: Power curves of two exemplary technology configurations

Two extreme turbine configurations are depicted in figure 5. The first one is the turbine with the lowest power density considered for this study; it is 1.6 $m^{2} / k W$. Its generator is $4 \mathrm{MW}$, and the diameter of its rotor blades is rather low at $90 \mathrm{~m}$. The second, more system-friendly technology configuration has a much higher power density at $6 \mathrm{~m}^{2} / \mathrm{kW}$. Its generator is only $2 \mathrm{MW}$, and the diameter of its rotor blades is considerably higher at $122.5 \mathrm{~m}$. Both configurations posses the same hub height of $80 \mathrm{~m}$. Besides, the frequency of wind speeds at a roughly typical German location is displayed, namely the frequency of wind speeds at the (current) benchmark location. From this we see that at most times, the systemfriendly turbine actually generates more electricity. Here, it does so in 72 percent of the time, whereas the system-unfriendly configuration only produces more 8 percent of the time. Moreover, as most used German project sites actually have worse wind conditions than the current definition of the benchmark location (Deutsche WindGuard, 2014), this comparison would be even more favorable for the system-friendly configuration there.

It is easy to see that the more system-unfriendly turbine can produce much more electricity at fairly strong winds, and that the alternative turbine is more efficient at medium-strong winds. This is even more apparent when plotting the power production relative to a turbine's nominal power, as depicted in figure 6 .

\subsection{Technology trade-off}

Investors face a trade-off between the three technology parameters generator size, hub height and rotor blade length. An increment in each of these categories leads to an increase in investment costs. In the model, the investor can opt for a range of combinations covering very system-friendly and system-unfriendly turbines. Based on the three technology parameters, the turbine's power curve is then calculated, as described in section 3.2.

Investment costs are held constant for this purpose, so that an investor has to optimize the relative costs and benefits of the three parameters and cannot simply opt for a configuration where all three are very large. Rough cost estimates from Deutsche WindGuard (2013) give $€ 1150$ per kw in generator size and $€ 410$ per $\mathrm{m}^{2}$ in rotor swept area. Averaging cost estimates for different 


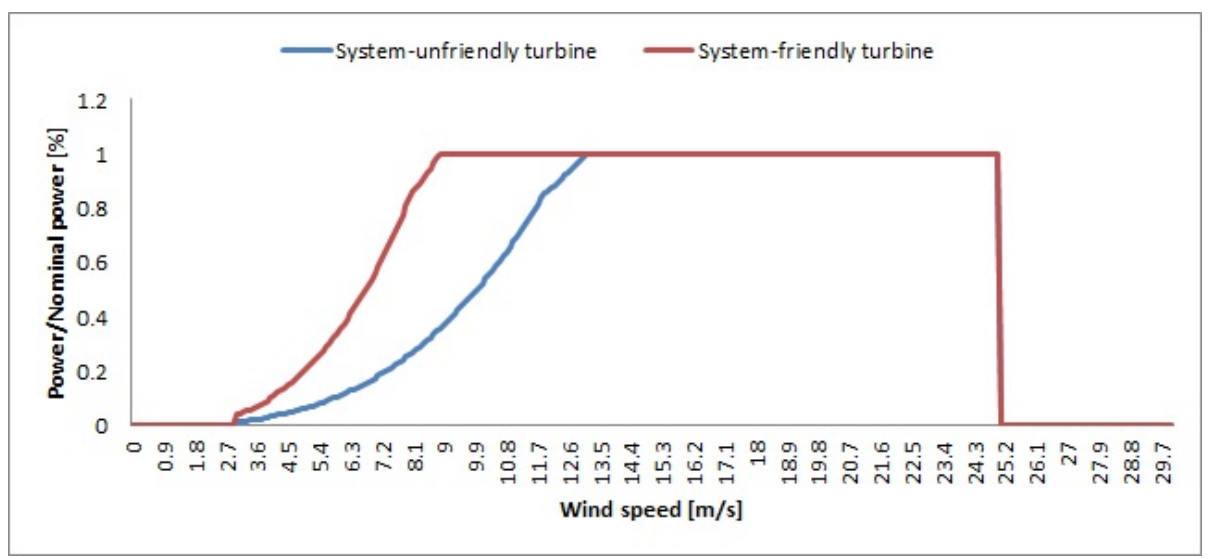

Figure 6: Relative power curves of two exemplary technology configurations

hub heights between 80 and 140m from Hau (2014) yield approximate costs of $€ 12500$ per meter hub height increase. The generator size lies between 2 and $4 \mathrm{MW}$, covering 91.5 percent of all sizes installed onshore in Germany in 2014. The rotor blade length lies between 45 and $61.7 \mathrm{~m}$, covering about 74 percent of new turbines, and finally the hub height lies between 80 and 140m, covering 76 percent of new onshore installations (Deutsche WindGuard, 2015).

As it turns out, the privately optimal investment decision always lies on one trajectory between on the one hand a very large generator $(4 \mathrm{MW})$, short rotor blades $(45 \mathrm{~m})$ and a low hub height $(80 \mathrm{~m})$, and on the other hand a fairly small generator $(2 \mathrm{MW})$, rather long rotor blades $(56.8 \mathrm{~m})$ and rather high hub height (140m).

\subsection{Wind speed data}

As input to the model, I use wind speed information for several locations, so that different average wind strengths and wind profiles are covered. All data is provided by Deutscher Wetterdienst (2015). The sites are Helgoland (SchleswigHolstein), Schwerin (Mecklenburg-Vorpommern), Bremen, Frankfurt (Main) (Hesse), Kahler Asten (North Rhine-Westphalia), Hohenpeissenberg (Bavaria) and Feldberg (Baden Württemberg). For the primary analysis, I employ data for 2013. A sensitivity analysis includes the data for 2012. In order to compute inputs into the future energy systems, 2006 is also used. When measurements for individual hours were missing, the arithmetic mean of the two neighboring existing measurements was taken.

The data on wind speeds has been measured at different heights than the turbines' hub heights. This requires height scaling. As commonly assumed, I assume a logarithmic vertical height profile, as described in Hau (2014). Knowing a wind speed at height $h 2$, the speed at height $h 1$ can be calculated by:

$$
v_{h 1}=v_{h 2} * \frac{\ln \frac{h 1}{z_{0}}}{\ln \frac{h 2}{z_{0}}}
$$

$z_{0}$ stands for the roughness length at the ground. It varies between locations. Urban places tend to have more obstacles, and thus the roughness length 
is higher, e.g. about 0.5 for Hanover. Rural places have lower values, e.g. Boltenhagen (German Baltic coast) rather has a value of 0.1 (Silva, J., Ribeiro, C., \& Guedes, 2000). Even if these values based on broader categorizations were not exactly correct, it would not spoil this analysis, as the focus of this study is not where turbines are allocated in the first place, but how the utilized technologies differ under different policy regimes.

\section{Results}

In every scenario, the investors optimize their NPV, taking the prevalent policy regime as exogenously given. I discuss the findings for one location at the German Baltic coast, Boltenhagen, as it is a location with intermediate wind speeds. The policy impacts on the technology decisions are robust across locations, unless stated otherwise.

Figure 7 provides an overview over the results for Boltenhagen: it depicts the annuitized remuneration amounts under the different schemes and the costs (investment costs plus operations and maintenance) per MWh. The fixed FIT leads to a relatively system-unfriendly configuration that minimizes costs ${ }^{13}$. Accounting for potential imperfect foresight and financing constraints, the MPS is modeled such that investors simply assume 2013's power price profile to remain in place. Based on this assumption, the MPS leads to only very limited incentives for a more system-friendly design; the slope - induced by 2013's power price profile - is largely flat. The slope of the future system value - measured as average obtained price in 2030 - touches the cost curve at the turbine that is system-optimal; it maximizes market value minus annuitized costs. In the example, it does so at a power density of $3.6 \mathrm{~m}^{2} / \mathrm{kW}$. The remuneration under the production value-based benchmark approach is parallel to the system value by design and thus leads to investors choosing the system-optimal turbine also from a private perspective. The change in benchmark location also differentiates according to system-friendliness, but does not reach the system-optimal turbine. The results are detailed in the following.

\subsection{Fixed FIT with default benchmark location}

This is the baseline scenario, simulating the policy regime in place in Germany from 2000 until 2012/2014. Figure 8 visualizes the trade-off investors face. It shows the trajectory described in section 3.3 , where the investor reduces generator size and increases both rotor blade length and hub height. Investors can on the one hand choose a high nominal power and a low rotor swept area, resulting in a low power density. On the other hand, they can opt for a low nominal power, but a larger rotor swept area, meaning a higher power density.

The results reveal that under these circumstances, investors opt for a turbine with a generator size of $2867 \mathrm{~kW}$ and a rotor swept area of $8504 \mathrm{~m}^{2}$, based on a rotor blade length of $51.3 \mathrm{~m}$. The power density is thus $3.0 \mathrm{~m}^{2} / \mathrm{kW}$, as shown in figure 7. Moreover, the hub height lies at $114 \mathrm{~m}$. This is in line with the empirical data we can observe in Germany: Rather large generators compared to the rotor

\footnotetext{
${ }^{13}$ Due to the default production volume-based benchmark approach, also the FIT already slightly distinguishes between the turbine designs
} 


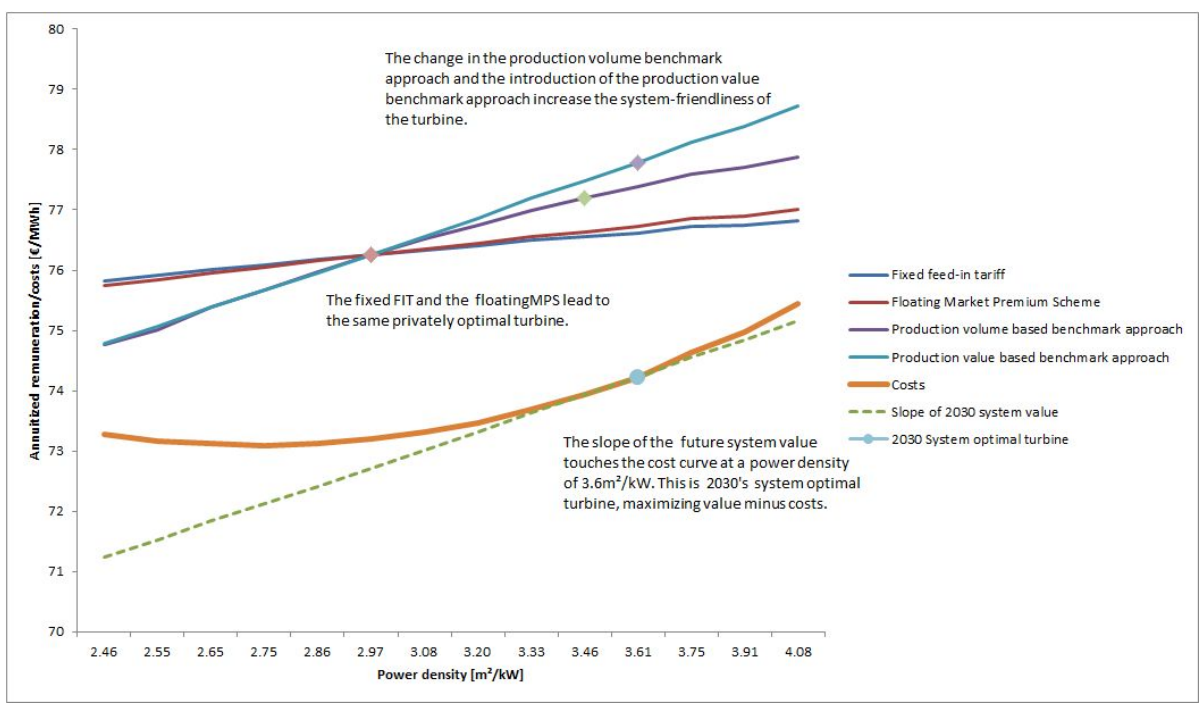

Figure 7: Remuneration and costs for Boltenhagen. For comparability, the levels of the MPS and the change in benchmark location have been set to equal the fixed FIT for the turbine that is chosen under the fixed FIT.

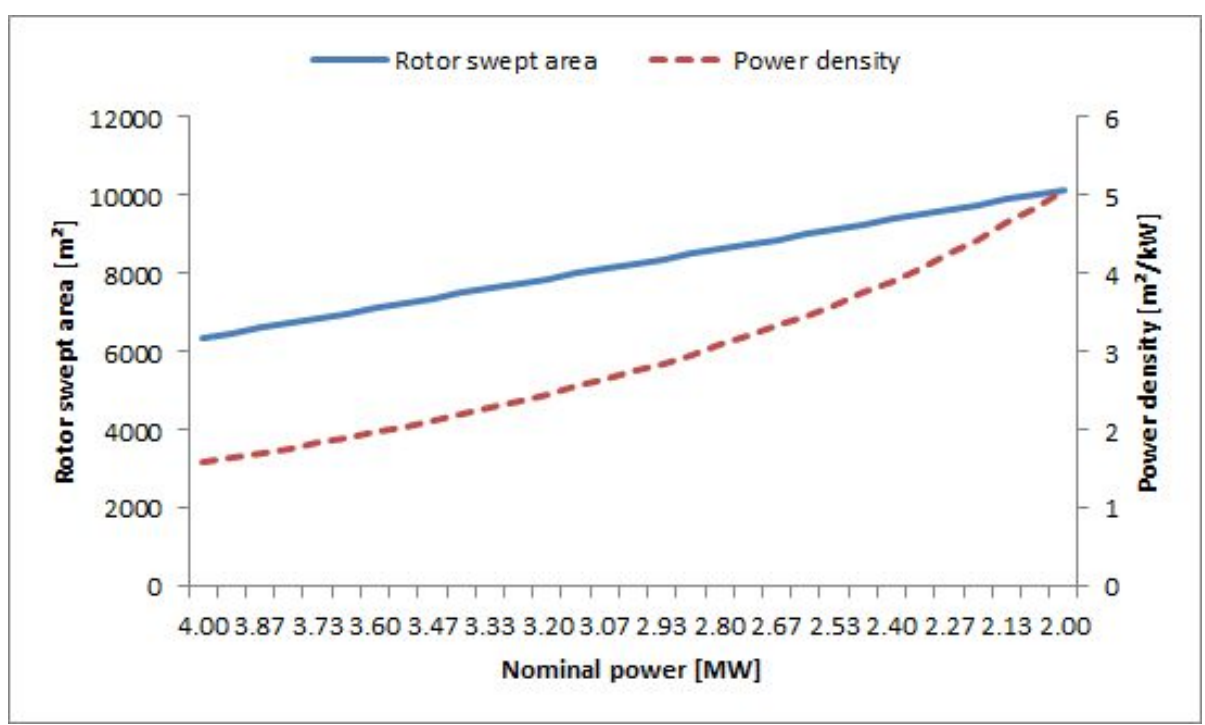

Figure 8: The turbines' technology configurations 


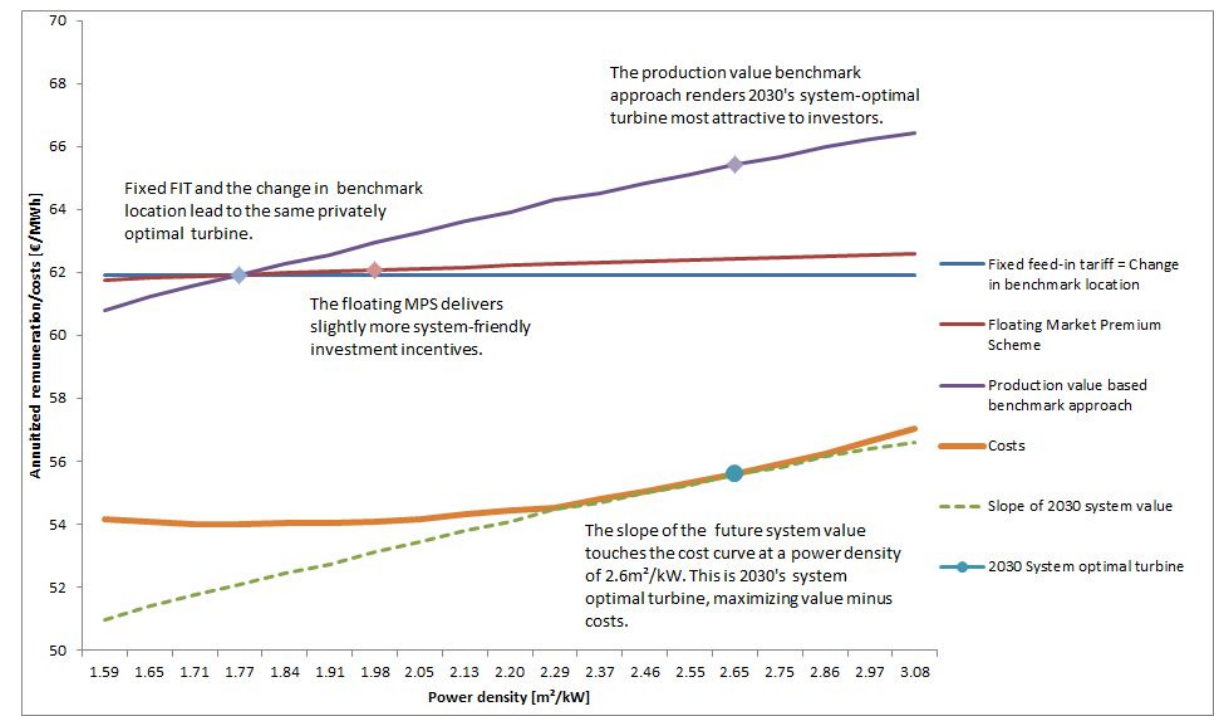

Figure 9: Remuneration and costs for Helgoland. For comparability, the level of the MPS has been set to equal the fixed FIT for the turbine that is chosen under the fixed FIT.

blade length, and thus low power densities. Such technology combinations yield, under the fixed FIT, the largest returns for investors.

For Helgoland, a site with more favorable wind conditions, the privatelyoptimal turbine under the FIT has a larger generator and shorter rotor blades and lower hub height. The power density is thus $1.8 \mathrm{~m}^{2} / \mathrm{kW}$. The systemoptimal turbine deviates almost 50 percent from this configuration, it has a power density of $2.6 \mathrm{~m}^{2} / \mathrm{kW}$ there. This is depicted in Figure 9 .

The model demonstrates that turbines with higher power densities lead to higher capacity factors. The turbines' production becomes more steady (compare Hirth (2015)), they have a higher number of full load hours and they produce a larger share of their production in times of weak and medium wind speeds. Figure 10 depicts the relationship between an increase in power density and an increase in capacity factors. Moreover, one can observe that also the mean production value, measured at the day-ahead market, is lower for lower power densities. Yet, the absolute variation is not high, with values between 3.61 cents $/ \mathrm{kWh}$ and 3.66 cents $/ \mathrm{kWh}$. The differential of .05 cents is about 1.4 percent of the electricity price. Nonetheless, also this measure hints at the higher value of electricity from more system-friendly turbine configurations.

\subsection{MPS with default benchmark location}

The main question with respect to the floating Market Premium Scheme is to what degree it impacts investors' technology decisions. The model yields that it does not or only slightly alter their optimal technology configuration at the scrutinized locations if they under-valuate future power price profiles due to imperfect foresight or financing constraints. Thus, the MPS fails to achieve one of its main intentions: to impact investment decisions and align the supply of 


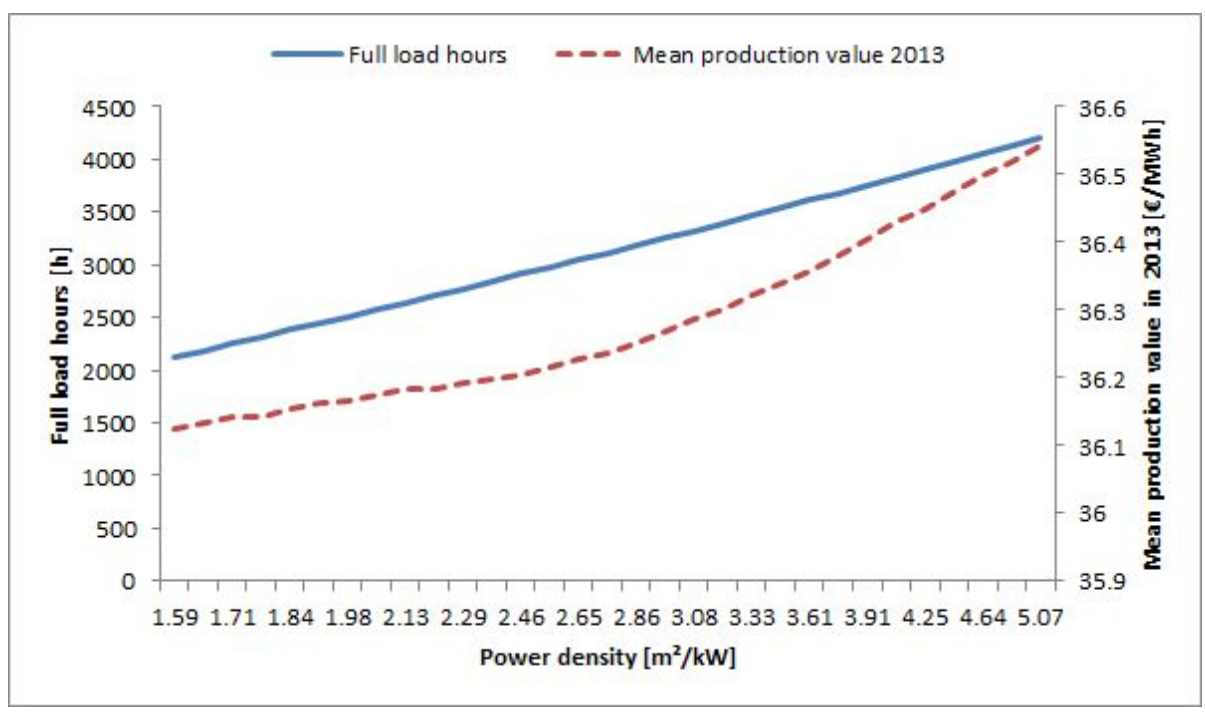

Figure 10: Characteristics of varying turbine configurations

wind energy with the demand for it. It hardly has any impact on the technology choice. The only effect is through the change in operations: As turbines are no longer operated in times of strongly negative prices, the average value of generated electricity rises by about 1-3 percent, depending on the location.

This result suggests that even though theoretically conceivable, it is not possible for investors to deviate systematically from the overall German wind generation through their turbine technology choice. With alternative configurations, they cannot produce systematically more at times of higher electricity prices under the current power price profile. At least under today's prices, $\operatorname{Cov}\left(\omega_{i, t, h}, \omega_{-i, t, h}\right)$ does not differ strongly for different turbine technologies. Thus, the electricity prices $p\left(\omega_{-i, t, h}\right)$ for different turbines lie too close together to impact revenues strongly enough to incentivize more system-friendly turbines, as shown in figure 10. That differential, 0.05 cents $/ \mathrm{kWh}$ between the most extreme turbine configurations represents only about 0.6 percent of the average initial feed-in payment of 8.9 cents/kWh. Thus, the floating market premium's slope in figure 7 remains mostly flat. All in all, the optimal investment decision stays (almost) the same as under the fixed FIT.

\subsection{Fixed FIT with adjusted benchmark location}

Implementing the change in the benchmark location has a more pronounced effect than switching to the MPS. More system-friendly turbines become more attractive to investors under a fixed FIT with adjusted benchmark location. For Boltenhagen, the optimized turbine configuration has a nominal power of $2600 \mathrm{~kW}$, a decrease of $267 \mathrm{~kW}$. The rotor swept area expands to $9008 \mathrm{~m}^{2}$, a plus of $504 \mathrm{~m}^{2}$. This is based on an increase in rotor blade length by $1.5 \mathrm{~m}$ to $53.5 \mathrm{~m}$. The resulting power density of $3.5 \mathrm{~m}^{2} / \mathrm{kW}$ lies $0.5 \mathrm{~m}^{2} / \mathrm{kW}$ or 16.8 percent above the baseline value. The hub height goes up by $8 \mathrm{~m}$ to $122 \mathrm{~m}$. The capacity factor rises by 3.2 percentage points to 40.4 percent. 


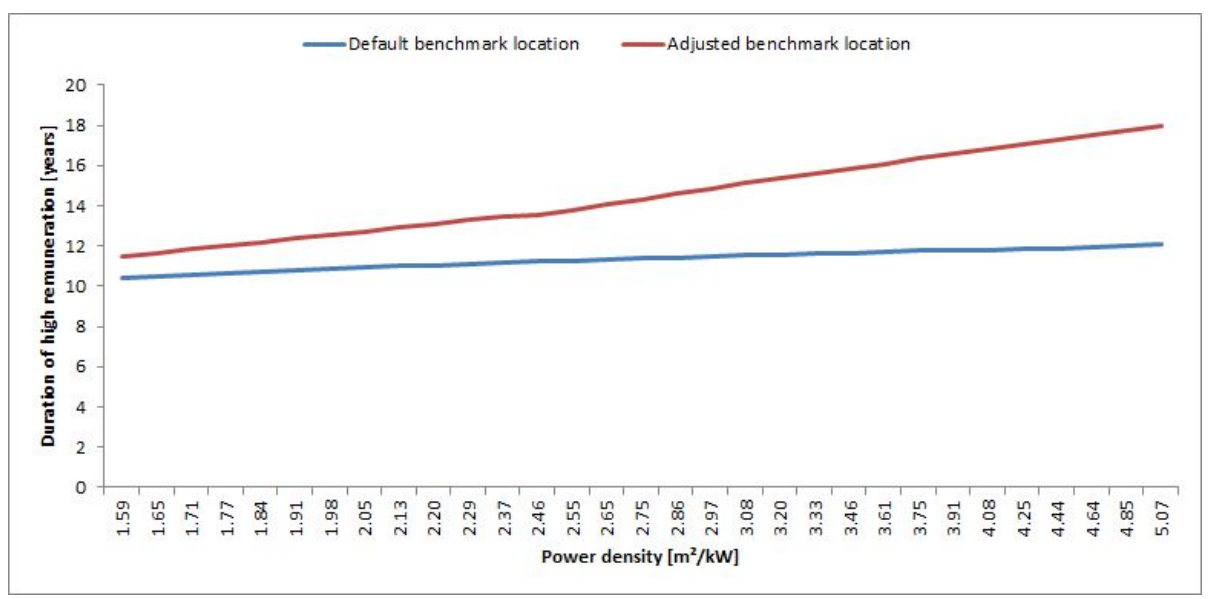

Figure 11: Duration of high initial feed-in payment under default and adjusted production volume-based benchmark approach for Boltenhagen

This is achieved through the aforementioned mechanism: the increase in the duration of the higher initial feed-in payments is larger for more system-friendly turbines. Figure 11 depicts the effect that the default and adjusted benchmark location have on the duration that the high initial payment is granted. Under the default production volume-based benchmark approach, there is few differences between the turbines. Those with high power densities are entitled to the higher payment hardly longer than the turbines with low power densities. In contrast, if the reference location under the production volume-based benchmark approach is adjusted, there is a strong distinction between turbine types. Turbines with high power density receive the high payment for almost 18 years, whereas those with low power densities receive it for about 12 years.

This effect is similar for all locations with mildly favorable wind resources, i.e. with benchmark ratios between 80 and 130 percent. Yet, this mechanism does not work at sites with very poor or good wind conditions: at sites with very poor wind resources (benchmark ratio $\zeta_{i}$ lies below 80 percent) (e.g. Hanover), all turbines are entitled to 20 years of the high feed-in payment in any case. There, the shift in the production volume-based benchmark approach does not effect the investment decision. Similarly, for sites with very favorable wind conditions with a benchmark ratio $\zeta_{i}$ of above 130 percent under the original definition (e.g. Helgoland, as shown in figure 9), they almost all continue to receive only 5 years of higher feed-in payment. Thus, they are not touched by the change in benchmark location ${ }^{14}$.

\subsection{Production value-based benchmark approach}

The production value-based benchmark approach manages to convey strong incentives to investors for them to alter their investment decisions. As shown

\footnotetext{
${ }^{14}$ The alteration of the benchmark location has also been combined with the MPS. Yet, since the incentives and the results in the original fixed FIT and the MPS are so similar, also changing the benchmark location has a similar effect on both. Therefore, the results of the MPS with new benchmark location are not reported here, but are similar to those reported.
} 
in Figures 7 and 9, the remuneration for the different turbines lies parallel to the value that these turbines provide to the system. Thus, investors will always choose the system-optimal turbine configurations.

For Boltenhagen, compared to the baseline, the optimally chosen turbine's nominal power is reduced by $333 \mathrm{~kW}$, whereas the rotor swept area increases by $630 \mathrm{~m}^{2}$, the rotor blade length rises by $1.9 \mathrm{~m}$, and the hub height goes up by $10 \mathrm{~m}$. This results in an increase in full load hours by 11 percent or equivalently an increase in capacity factor of 4 percentage points. Importantly, the share of the production shifts to times of lower wind speeds with ceteris paribus higher electricity values. For lower wind speeds $(<5 \mathrm{~m} / \mathrm{s})$ (constituting about 30 percent of the time in Boltenhagen), the (generally low) number of full load hours increases by 23 percent. For medium wind speeds $(<10 \mathrm{~m} / \mathrm{s}$ and $\geq 5 \mathrm{~m} / \mathrm{s}$, about 50 percent of the time), this increase is 20 percent, and for strong winds $(\geq$ $10 \mathrm{~m} / \mathrm{s}$, about 20 percent) it remains equal.

At wind-rich sites like Helgoland where the system-optimal turbine deviates furthest from the privately-optimal one under the fixed FIT, the production value-based benchmark approach has the strongest impacts: It adjusts investors' investment decisions by 49 percent of the original power density, increasing the number of full load hours by 18 percent and shifting the production into hours with a higher value.

To sum it up, this policy conveys stronger incentives to investors to alter their investment decision than the change in benchmark location or the MPS. Unlike the former, this works for all kind of sites, independent of their benchmark ratio.

\section{Conclusion}

Renewable energies like wind energy play an increasingly-important role in the German electricity sector. However, the power generation profile of wind turbines differs greatly from conventional thermal plants. In an energy system with a very high share of variable renewable energies, there is the need for a more flexible system - e.g. through dispatchable backup capacity, storage and demand side response measures. The need for such flexibility can be reduced through the choice of more system-friendly wind turbines. In line with previous literature I argue that through their technology configurations, certain wind turbines provide more value to the energy system. In particular, wind turbines with a higher ratio between area swept by their rotor and their generation capacity, and with a greater hub height, are considered to be more system-friendly. They are able to generate a larger share of their electricity during low and medium wind speeds.

In order to analyze the different policies' effects, I have modeled investors' behavior via an investment model. Investors are assumed to maximize the net present value of their wind power project.

The introduction of the floating market premium scheme aimed at changing investors' investment decisions by incentivizing the alignment of wind energy supply and its demand. I demonstrate through which mechanism investors' behavior could be influenced, namely through the covariance between a turbine's power generation and the overall German wind power generation. Assuming that investors are constrained by imperfect foresight and are bound to conservative power price profile developments due to their financing structure, I show 
that the floating MPS fails to align wind power supply and demand. Based on the 2013 power price profile, the floating MPS has hardly any impact on the technology decision of investors. It primarily decreases production in times of highly-negative electricity prices, but hardly any technology investment decisions are altered.

In contrast, the results indicate that in order to increase the value of the electricity produced by a wind turbine, a change in the production volume-based benchmark approach manages to influence technology investors' choices. Due to longer periods with high feed-in payments for more system-friendly turbines, investors have financial incentives to install such turbines. Those turbines produce at higher capacity factors, and at higher values of their electricity. This shift brings the chosen technology parameters closer to what has been identified as optimal from a system-perspective in Molly (2014), Hirth (2015) and Fraunhofer IWES (2013b). However, the policy does not succeed for locations with very favorable or very poor wind conditions, which constituted about 50 percent of all installations between 2009 and 2011 (Deutsche WindGuard, 2014).

The production value-based benchmark approach takes future energy systems' prices into account. Based on the fixed feed-in tariff, an adjustment to the remuneration amount is made dependent on the average electricity value at which a turbine produces in $2030^{15}$. Through this variation, a strong adjustment in investment behavior is accomplished, since investors can now fully integrate the additional value of system-friendly turbines into their projected cash flows. The adjustment in technology is more pronounced than under a change in the production volume-based benchmark approach. Moreover, this holds for all locations, independent of their wind quality. Yet, an additional requirement of this approach is that regulators need to project power price profiles that are based on the hourly and location specific wind pattern of a pre-defined year (or set of years) that needs to be made available to investors. This analysis can be expanded by exploring if adjustments are necessary with regard to the construction of wind parks. Losses in the wind energy content through shading might differ across wind turbine types and thus justify further adjustments. Furthermore it needs to be assessed how robust the results for wind turbine choices are to changes to system parameters, to the question of whether it suffices to select one historic reference year of wind output or whether multiple years are required, and whether to use a 2030 projection of power price profiles or a combination for a period of years.

\footnotetext{
${ }^{15}$ The snapshot 2030 being only one possible future year to consider. Further research could investigate how long a period to consider with what discount rate.
} 


\section{References}

Agora Energiewende. 2015. Die Energiewende im Stromsektor: Stand der Dinge 2014. Berlin.

Bundesministerium für Wirtschaft und Energie. 2015. Erneuerbare Energien im Jahr 2014. Berlin.

Bundestag. 2014. "Gesetz zur grundlegenden Reform des ErneuerbareEnergien-Gesetzes und zur Änderung weiterer Bestimmungen des Energiewirtschaftsrechts." (33): 1066-1132.

Butler, Lucy, and Karsten Neuhoff. 2008. "Comparison of feed-in tariff, quota and auction mechanisms to support wind power development." Renewable Energy, 33(8): 1854-1867, DOI: http://dx.doi.org/10.1016/j. renene.2007.10.008.

Cludius, Johanna, Hauke Hermann, Felix Chr Matthes, and Verena Graichen. 2014. "The merit order effect of wind and photovoltaic electricity generation in Germany 20082016: Estimation and distributional implications." Energy Economics, 44 302-313, DOI: http://dx.doi.org/10.1016/ j.eneco.2014.04.020.

Deutsche WindGuard. 2013. Kostensituation der Windenergie an Land in Deutschland. Varel.

Deutsche WindGuard. 2014. Vergütung von Windenergieanlagen an Land über das Referenzertragsmodell. Comissioned by Agora Energiewende. Varel.

Deutsche WindGuard. 2015. Status des Windenergieausbaus an Land in Deutschland 2014. Varel.

Deutscher Wetterdienst. 2015. Climate Data Germany: Wind. Offenbach.

Deutsches Zentrum für Luft-und Raumfahrt. 2014. Möglichkeiten und Grenzen des Lastausgleichs durch Energiespeicher, verschiebbare Lasten und stromgeführte KWK bei hohem Anteil fluktuierender erneuerbarer Stromerzeugung. Stuttgart.

Enercon. 2012. ENERCON product overview. Aurich.

European Energy Exchange. 2015. EEX data. Leipzig.

Fraunhofer IWES. 2013a. Entwicklung der Windenergie in Deutschland. Comissioned by Agora Energiewende. Kassel.

Fraunhofer IWES. 2013b. Wie wird sich die Windenergietechnik in Deutschland weiterentwickeln?. Comissioned by Agora Energiewende. Kassel.

Gawel, Erik, and Alexandra Purkus. 2013. "Promoting the market and system integration of renewable energies through premium schemes - A case study of the German market premium." Energy Policy, 61 599-609, DOI: http://dx.doi.org/10.1016/j.enpol.2013.06.117. 
Grothe, Oliver, and Felix Müsgens. 2013. "The influence of spatial effects on wind power revenues under direct marketing rules." Energy Policy, 58 237-247, DOI: http://dx.doi.org/10.1016/j.enpol.2013.03.004.

Hau, Erich. 2014. "Wind Resources." In Wind Turbines. Berlin, Heidelberg: Springer, Chap. 13 505-548, DOI: http://dx.doi.org/10.1007/ 978-3-642-28877-7.

Hirth, Lion. 2013. "The market value of variable renewables." Energy Economics, 38 218-236, DOI: http://dx.doi.org/10.1016/j.eneco.2013.02. 004.

Hirth, Lion. 2015. System-friendly wind and solar power. Presented at the IEWT conference 2015, Vienna.

Joskow, Paul. 2011. "Comparing the Costs of Intermittent and Dispatchable Electricity Generating Technologies." American Economic Review, 101(3): 238-241, DOI: http://dx.doi.org/10.1257/aer.100.3.238.

Molly, J P. 2011. "Rated Power of Wind Turbines : What is Best?." DEWI Magazine (38): 49-57.

Molly, J P. 2012. "Design of Wind Turbines and Storage : A Question of System Optimisation." DEWI Magazine (40): 23-29.

Molly, J P. 2014. "New Specific Power Installation in Wind Turbines." DEWI Magazine (44): 32-34.

Narbel, Patrick A., Jan Petter Hansen, and Jan R. Lien. 2014. "Energy Technologies and Economics." Cham: Springer International Publishing, , DOI: http://dx.doi.org/10.1007/978-3-319-08225-7.

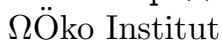

Öko Institut. 2014. Erneuerbare-Energien- Gesetz 3.0 (Langfassung). Comissioned by Agora Energiewende. Berlin.

REN21. 2014. Renewables 2014 - Global Status Report. Paris.

Schmidt, J., G. Lehecka, V. Gass, and E. Schmid. 2013. "Where the wind blows: Assessing the effect of fixed and premium based feed-in tariffs on the spatial diversification of wind turbines." Energy Economics, 40 269-276, DOI: http://dx.doi.org/10.1016/j.eneco.2013.07.004.

Sensfuß, Frank, Mario Ragwitz, and Massimo Genoese. 2008. "The merit-order effect: A detailed analysis of the price effect of renewable electricity generation on spot market prices in Germany." Energy Policy, 36(8): 3086-3094, DOI: http://dx.doi.org/10.1016/j.enpol.2008.03.035.

Silva, J., Ribeiro, C., \& Guedes, R. 2000. "Roughness length classification of Corine Land Cover classes." In Proceedings of the European Wind Energy Conference, Milan, Italy. 1-10.

Tisdale, Matthew, Thilo Grau, and Karsten Neuhoff. 2014. "EEG Reform Impact on Wind Generator Project Finance." DIW Berlin Discussion Paper \#138\%. 
Ueckerdt, Falko, Lion Hirth, Gunnar Luderer, and Ottmar Edenhofer. 2013. "System LCOE: What are the costs of variable renewables?." Energy, 63 61-75, DOI: http://dx.doi.org/10.1016/j.energy.2013.10.072.

Würzburg, Klaas, Xavier Labandeira, and Pedro Linares. 2013. "Renewable generation and electricity prices: Taking stock and new evidence for Germany and Austria." Energy Economics, 40 S159-S171, DOI: http: //dx.doi.org/10.1016/j.eneco.2013.09.011. 